\title{
Comparison between Chronological Age and Dental Ages of Saudi Patients with Cleft Lip and Palate
}

\author{
Naif A Bindayel ${ }^{1}$, Maan Alsultan², Samar El Hayek ${ }^{3}$, Khalid Almoammer ${ }^{4}$
}

\begin{abstract}
Aim: The primary aim of this study is to compare the chronological age with the dental age of Saudi patients with non-syndromic cleft lip and palate (CLP). The patients' demographics (gender and age group) were analyzed further.

Materials and methods: In total, 401 panoramic radiographs were assessed (195 and 206 for the control and the CLP groups, respectively). The subjects' ages ranged from 3 to 17 years, from both genders. The root and crown developmental stages of the mandibular permanent teeth were evaluated using Demirjian's method to calculate dental age. The subjects were separated into three groups according to chronological age. One investigator collected all the data, the intra-class correlation (ICC) coefficient test showed good reliability (0.984). A paired $t$ test was then used to determine any statistically significant difference between the mean dental and chronological ages of the control and the cleft samples. The mean difference between chronological and dental ages was then calculated for the control and the cleft groups. A Student's $t$ test was then used to compare the two mean differences.

Results: The dental age of normal subjects was ahead of their chronological age by 8.1 months. The CLP group had delayed dental development by 9.6 months $(p<0.01)$ when compared with normal subjects. The males with CLP had an extended delay in dental development by 6.5 months when compared with females with CLP.

Conclusion: Saudi subjects affected with CLP had significantly delayed dental development when compared with the control group.

Clinical significance: Dental age is commonly used to assess dental development in comparison with chronological age. Reporting dental age accuracy for CLP cases would be of value for proper management and diagnosis.

Keywords: Age, Chronological, Cleft, Dental, Lip, Palate.

The Journal of Contemporary Dental Practice (2019): 10.5005/jp-journals-10024-2566
\end{abstract}

\section{INTRODUCTION}

Cleft lip and palate (CLP) is considered to be the most common craniofacial birth defect with a worldwide incidence of 1 in 500 1,000 births. ${ }^{1}$ The incidence of clefting is reported to be the highest among the Asian population. ${ }^{2}$ In Saudi Arabia, no nationwide study has assessed the exact number of people with CLP. However, a study conducted in Riyadh (Saudi Arabia) showed the incidence of facial clefts as 0.3 per 1,000 live births. $^{3}$

Individuals with cleft lips or cleft palates or both usually present with tooth abnormalities in number, position, and shape. The incidence of hypodontia away from the cleft area is increased compared with people without a cleft. ${ }^{4-6}$ Hypodontia most commonly affects the upper and the lower second premolars and the upper lateral incisor on the noncleft area. ${ }^{5}$ In Saudi Arabia, Al-Kharboush et al. found that two-thirds of their unilateral CLP sample had at least one missing tooth. ${ }^{7}$

Dental age is one of the three designations of physiological maturity, besides skeletal age and somatic age. An accurate estimation of dental age is a key tool in forensic dentistry. Moreover, it is of clinical importance in pediatric dentistry and orthodontics. Dental and skeletal ages are considered essential biological age indicators of an individual. Skeletal age is more influenced by external, environmental, hormonal, and nutritional factors and not well correlated with chronological age. ${ }^{8,9}$ However, dental age evaluation in comparison with chronological age is considered less dependent on the impact of external and internal factors. ${ }^{10,11}$ Among the other indicators of maturity, dental age is associated with less variability when compared with chronological age. ${ }^{12,13}$ Due to its credibility, dental age has also been used in estimating the age of children without knowing their date of birth. ${ }^{13}$
1,2,4 Department of Pediatric Dentistry and Orthodontics, College of Dentistry, King Saud University, Riyadh, Kingdom of Saudi Arabia

${ }^{3}$ Dental Department, King Abdulaziz Medical City, Ar Rimayah, Riyadh, Kingdom of Saudi Arabia

Corresponding Author: Naif A Bindayel, Department of Pediatric Dentistry and Orthodontics, College of Dentistry, King Saud University, Riyadh, Kingdom of Saudi Arabia, Phone: +966 114677230, e-mail: nbindayel@ksu.edu.sa

How to cite this article: Bindayel NA, Alsultan M, et al. Comparison between Chronological Age and Dental Ages of Saudi Patients with Cleft Lip and Palate. J Contemp Dent Pract 2019;20(5):603-608.

\section{Source of support: Nil}

Conflict of interest: None

Several methods have been utilized to estimate dental age using radiographs. ${ }^{14,15}$ Nolla's method was based on identifying 10 stages of dentition calcification. ${ }^{16}$ Haavikko et al. recommended estimating dental age by determining 1 out of 12 radiographic distinct stages of four permanent teeth. ${ }^{17}$ A new method of estimating dental age was introduced by Cameriere et al. who measured the open root apices in seven mandibular teeth. ${ }^{14}$ Demirjian's method depended on identifying the eight radiographic stages $(\mathrm{A}-\mathrm{H})$ describing the root and crown development in the permanent mandibular dentition of French-Canadian children, not including the third molar. ${ }^{15}$ Demirjian's method has been thoroughly used in research to determine dental age and assess dental maturation. ${ }^{18-23}$

Different studies were done to evaluate the correlation between chronological age and dental age. The variability of dental

() The Author(s). 2019 Open Access This article is distributed under the terms of the Creative Commons Attribution 4.0 International License (https://creativecommons. org/licenses/by-nc/4.0/), which permits unrestricted use, distribution, and non-commercial reproduction in any medium, provided you give appropriate credit to the original author(s) and the source, provide a link to the Creative Commons license, and indicate if changes were made. The Creative Commons Public Domain Dedication waiver (http://creativecommons.org/publicdomain/zero/1.0/) applies to the data made available in this article, unless otherwise stated. 
development has been shown to exist in different populations, such as between the French-Canadian and Finnish, ${ }^{24}$ Dutch, ${ }^{21}$ Swedish, ${ }^{25}$ Polish, ${ }^{26}$ Indian, ${ }^{11}$ Norwegian, ${ }^{27}$ British, ${ }^{28}$ South German, ${ }^{29}$ and Korean children. ${ }^{30}$

A group of Finnish children had increased dental maturation when compared with French-Canadian subjects $(p<0.01) .{ }^{24}$ In a sample of Dutch children, a significant difference was found where the boys and girls were 0.4 and 0.6 year ahead of the French-Canadian, respectively. ${ }^{21} \mathrm{~A}$ frequently reported finding in Demirjian's method was its potentially increased dental age when compared with its chronological age, ${ }^{25-30}$ strengthening the need to adjust the method for a specific population. Demirjian's method was modified by adapting it to the dental age estimation in the Belgian population, which accurately estimated the dental age compared with the original method. ${ }^{22}$

A few studies reported a high correlation between dental and chronological ages based on Demirjian's method of estimating dental age. In a sample of Indian children, the mean difference between chronological age and dental age was 0.14 year in boys and -0.04 year in girls $(r=0.988) .{ }^{11}$ Another study reported a statistically significant positive correlation $(r=0.878)$ between chronological and dental ages. ${ }^{31}$

Several studies showed a significant developmental delay in permanent teeth of CLP children, with a range of 0.3 to 0.7 year. ${ }^{5,32-38}$ Many variables affected the extent of dental delay, the dentition developmental stage, skeletal jaw positioning, and the severity of the clefting affecting the lip and palate, including defects' laterality. ${ }^{5,38-40}$ Additionally, some studies showed that boys with clefts were more dentally delayed than girls. ${ }^{34,41-43}$

In assessing panoramic and hand-wrist radiographs, Al-Hadlaq et al. did not demonstrate statistically significant difference among 148 Saudi male children's mean chronological, dental, and skeletal ages. ${ }^{44}$ However, Al-Emran examined panoramic radiographs of 430 Saudi boys and girls and showed $(p<0.05)$ advance dental age in comparison with their chronological age. ${ }^{45}$ Another study on Saudi children showed a much higher mean increase in the dental ages. ${ }^{46}$ In contrast, a study on Kuwaiti children reported a delay in dental age compared with the French-Canadian standards. ${ }^{47}$

Surgical procedures are usually needed to repair oral clefts, such as the alveolar bone grafts, and the proper timing of such interventions would rely on the child's stage of development. For this reason, further investigations on developmental disorders are needed to gain more insights into their origins, allowing for more appropriate therapeutic approaches. No previous studies assessed the dental development of Saudi patients with CLP. Therefore, this study was conducted to compare chronological and dental ages of Saudi patients with non-syndromic CLP.

\section{Materials and Methods}

In total, 400 subjects would be needed (200 each for the control and the studied groups), ${ }^{48}$ to detect a difference of up to 1 month, under a power of $80 \%$ and with a 0.05 level of significance, based on a previous study. ${ }^{45}$ All subjects were recruited from three major CLP treatment centers in Riyadh, Saudi Arabia, and the research conduction was reviewed and approved by the Clinical Review Administration (No. 3284). Subjects with complete dental development (18years and over), missing record items, craniofacial syndromes, and known systemic diseases were excluded from the study. Matching exclusion criteria were used for the control group subjects who were not affected with CLP.
The subjects were segregated into three groups according to chronological age (under 8, 8-12, and over 12 years old). All subjects had a complete dental history section and panoramic radiographs. Each subject's dental age was calculated by one investigator using Demirjian's method. ${ }^{15}$ The method utilized seven mandibular permanent left dentition and assesses its development. Dental development is classified into eight stages $(\mathrm{A}-\mathrm{H})$, with four criteria being defined for each tooth out of the seven included in the analysis. This aids in completing a scoring system for each tooth that illustrates dental maturity in which dental age can be concluded through the use of a conversion table. Furthermore, each subject's chronological age was calculated as the positive difference between the date of birth indicated by the patient's record and the panoramic radiograph date. Age and gender were included as the demographic variables. Other potential confounding factors were collected, including laterality (unilateral vs bilateral cleft).

To answer this study's main question, the comparison was designed to differentiate between the CLP and the control groups. Initially, chronological and dental ages were compared; subsequently, the differences between each group were compared.

Ten panoramic radiographs chosen at random were analyzed twice by the same investigator, using Demirjian's method before the data collection phase. The ICC test was used to assess the intraexaminer reliability of the applied method. A high level of reliability was shown as the result was 0.984 .

All data were then analyzed using Statistical Package for the Social Sciences (SPSS) 20 software. Descriptive statistics (mean, median, and range) were presented for each of the variables. A paired $t$ test was used to test for any statistically significant difference between the dental and the chronological ages in each group (CLP and control). Next, Student's $t$ test was used to compare the calculated mean difference between the chronological and the dental ages of the control and the CLP groups. Figure 1 summarizes the study design and the statistical tests used.

\section{Results}

All investigated subjects had CLP. In total, 1,500 files were screened in order until the needed sample size was obtained; 401 subjects were included (195 and 206 for the control and the CLP groups, respectively). The subjects' ages ranged from 3 to 17 years, from both genders. Table 1 shows subjects' distribution in the control and the CLP groups, with the averages and the ranges of their chronological and dental ages.

When the mean chronological and dental ages were compared using a paired $t$ test, only the control group demonstrated a statistically

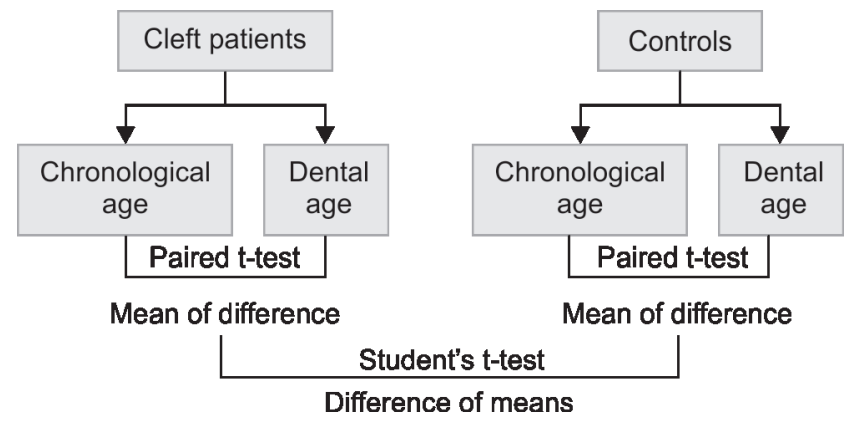

Fig. 1: The study design and statistical tests applied 
Table 1: Descriptive data of the CA and DA for the control and CLP groups

\begin{tabular}{llllrl}
\hline & $N$ & Minimum & Maximum & Mean & Std. deviation \\
\hline CA (control) & 195 & 3.00 & 17.00 & 9.50 & 2.95 \\
DA (control) & & 3.00 & 15.80 & 10.21 & 2.98 \\
CA (cleft) & 206 & 4.30 & 17.30 & 9.77 & 2.81 \\
DA (cleft) & & 3.30 & 16.00 & 9.65 & 2.84 \\
\hline
\end{tabular}

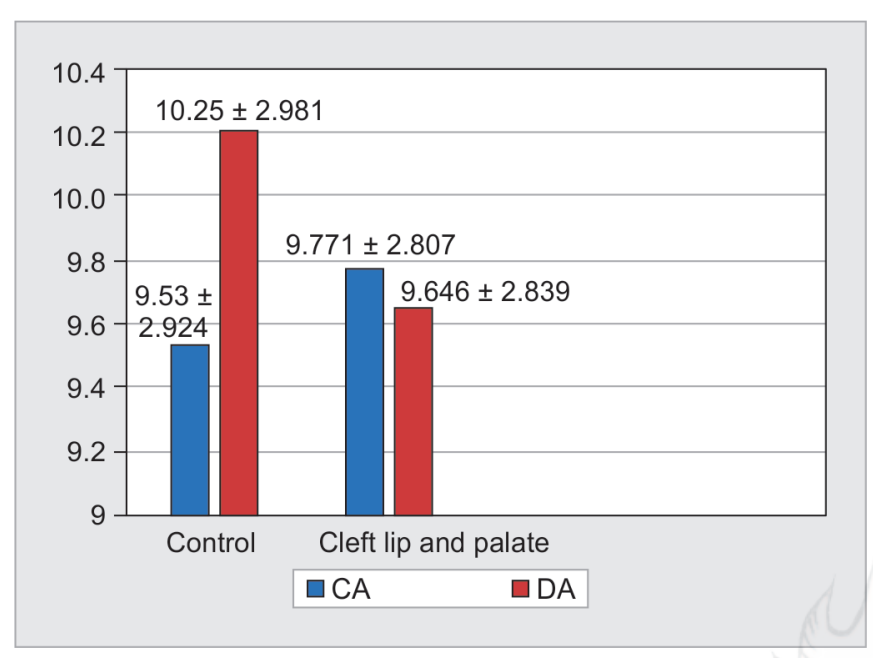

Fig. 2: Comparison between the chronological age (CA) and dental age (DA) for the control and the cleft group using paired $t$ test ( $p$ values for control and cleft group comparison are $<0.01$ and 0.246 , respectively)

significant difference (Fig. 2). The dental age of the control subjects was 8.1 months ahead of their chronological age. In contrast, the dental age of the CLP subjects was delayed by 1.5 months compared with their chronological age. However, it was not statistically significant $(p=0.246)$.

The calculated mean difference between the chronological and the dental ages of the control and the CLP groups was further compared using a $t$ test. A difference of 9.6 months was found to be statistically significant $(p<0.01)$. The CLP group had delayed dental development by 9.6 months when compared with normal subjects.

The effect of gender on dental development was further investigated. Neither a statistically significant nor a clinical

Table 2: Comparison between the CA and DA means ( mean $=C A-D A)$ for males and females in the control and cleft groups

\begin{tabular}{|c|c|c|c|c|c|c|}
\hline & & $N$ & Mean & $\begin{array}{l}\text { Std. } \\
\text { deviation }\end{array}$ & $\begin{array}{l}\text { Mean } \\
\text { difference }\end{array}$ & $p$ value \\
\hline \multirow[t]{2}{*}{ Control } & Male & 103 & -0.665 & 1.619 & 0.021 & 0.119 \\
\hline & Female & 92 & -0.686 & 1.204 & & \\
\hline \multirow[t]{2}{*}{ Cleft } & Male & 118 & 0.359 & 1.591 & $0.545^{*}$ & 0.012 \\
\hline & Female & 89 & -0.186 & 1.429 & & \\
\hline
\end{tabular}

Table 4: The laterality of the cleft site (unilateral vs bilateral) among the CLP sample

\begin{tabular}{lcrlll}
\hline & $N$ & Mean & Std. deviation & Mean difference & $p$ value \\
\hline Unilateral & 53 & -0.351 & 1.209 & $-0.882^{*}$ & 0.026 \\
Bilateral & 26 & 0.531 & 2.244 & & \\
\hline
\end{tabular}

${ }^{*} p<0.05$

difference was found in the control group. Nevertheless, the males with CLP had an extended delay in dental development by 6.5 months when compared with females with CLP (Table 2). Females seemed to be affected with a lesser degree of delayed dental development, with their dental age ahead of their chronological age by only 2.2 months.

Table 3 shows the distribution of the three segregated groups according to the chronological age of both the control and the CLP groups. When the mean difference between the chronological and the dental ages of the age subgroups was compared, only the CLP group showed statistically significant differences in the analysis of variance (ANOVA) test ( $p$ value $=0.003$ and 0.119 for the CLP and the control age subgroups, respectively). Statistically significant trends indicated dental age ahead of chronological age early in life (below 8 years, with 4.4 months on average), approximated it in the mixed dentition period (8-12 years), and showed a delayed dental age at an older age compared with chronological age (over 12 years, with 7.1 months).

The laterality of the cleft site (unilateral vs bilateral) was recorded in the medical records of 79 patients only. This criterion was shown to influence the relationship between dental and chronological ages. On average, the subjects with bilateral cleft had an increased delay in dental development by 10.6 months (Table 4) compared with the subjects with unilateral cleft.

\section{Discussion}

Some dentofacial anomalies are known to affect the development and the growth of certain associated structures (e.g., hemifacial microsomia and craniosynostosis). In particular, dental development and the timing of teeth emergence in the oral cavity are two of the signs observed in relation to these defects, ${ }^{49,50}$ with CLP as one of the anomalies affecting dental development. ${ }^{5,32-38}$

Dental age is commonly used to assess dental development progress in relation to chronological age. The relevant literature presents many earlier proposed methods. In Nolla's method, the increased multiple stages presented have rendered precision assessment compromise with associated application difficulties. ${ }^{51,52}$ Haavikko's method was considered a superior way of defining dental age but was found to underestimate dental age. ${ }^{25,53}$ The present study utilized Demirjian's method of dental age assessment. ${ }^{15}$ It is one of the easily applied and practical methods used for calculating dental age. ${ }^{18-23}$

Although Demirjian's method was shown as highly valid, ${ }^{27,28}$ and reliable, ${ }^{30,54}$ in terms of reflecting the chronological age of the

Table 3: Comparison between the CA and DA means difference (mean difference $=C A-D A$ ) for different age subgroups among the control and cleft samples

\begin{tabular}{|c|c|c|c|c|c|c|}
\hline & \multicolumn{3}{|c|}{ Control group } & \multicolumn{3}{|c|}{ Cleft lip and palate group } \\
\hline & $N$ & Mean difference & Std deviation & $N$ & Mean difference & Std deviation \\
\hline Below 8 years & 52 & -0.947 & 1.668 & 51 & $-0.365^{* \dagger}$ & 0.992 \\
\hline $8-12$ years & 93 & -0.654 & 1.032 & 88 & $0.062^{* \neq}$ & 1.302 \\
\hline Above 12 years & 50 & -0.436 & 1.773 & 67 & $0.592^{\dagger \neq}$ & 2.010 \\
\hline
\end{tabular}

${ }^{*} p<0.05$ (0.045), ${ }^{\dagger} p<0.01(0.002),{ }^{\ddagger} p<0.05(0.049)$ 
subjects, deviations were observed when the method was used on other populations and ethnicities. Korean children demonstrated advancement in dental age. ${ }^{30}$ Other populations showed similar deviations in varying degrees. ${ }^{11,21,24-30}$

Therefore, this study was designed to use Demirjian's method as a reference point for comparing a control group and an affected group rather than as a testing tool. Investigating the chronological and the dental ages of a single group of affected patients would not provide a valid comparison, knowing the ethnicity variations. ${ }^{27-30}$ Thus, Demirjian's method was employed to compare the differences between the chronological and the dental ages of both CLP and control groups (Fig. 1).

The mean chronological and dental ages of both groups spanned from 9 to 10 years, with the subjects ranging from 3 to 17 years old. This age range constitutes different stages of dental development, allowing investigating variant potential discrepancy.

The control group demonstrated a statistically significant difference when the mean chronological and dental ages were compared (Fig. 2). The dental age of the control subjects was ahead by 8.1 months, supporting the result of an earlier study on the same population. Al-Emran showed an advancement by 4.2 months on average in a healthy Saudi population sample. ${ }^{45}$ Other studies documented the same range of advancement. ${ }^{44,45}$

The dental age of the CLP group was delayed by 1.5 months compared with its chronological age. Although not statistically significant, this finding is consistent with the reported studies in the literature showing a delayed dental age compared with the chronological age. In a study involving 182 children with CLP in the United States, Pham et al. demonstrated a delay of 7.2 months in the subjects' dental ages compared with their chronological ages. ${ }^{34}$

To achieve the main aim of the present study, the calculated difference between the chronological and the dental ages of the control and the CLP groups was compared, as indicated in the study design. The CLP group had delayed dental development by 9.6 months when compared with normal subjects. The noticeable increase in the span of delayed development could be due to the ethnicity variation resulting from the comparison to the proper reference point (i.e., the Saudi control group). This finding also aligns with the general clinical observation of a delayed dental age by 1 to 2 years in the studied population. However, most of the literature indicated a lesser period of delayed dental development of the CLP group, ranging from 0.3 to 0.7 year. ${ }^{5,32-38}$ Lai et al. noted a mean delay of 4.4 months in the tooth formation of a sample of 231 children with CLP, who were 3 to 12 years old and from Southern China, relative to children without a cleft. ${ }^{33}$

In contrast to the control group, the males with CLP showed an extended delay in dental development compared with their female counterparts. The relevant literature previously identified males as having delayed dental development. ${ }^{34,35,41-43}$ Borodkin et al. reported that males were more dentally delayed than females, with an average difference of 0.96 year. ${ }^{43}$ This could be associated with the relative delay in teeth development and emergence between boys and girls, with the former attaining their complete dentition 1 year earlier. Other studies identified the same variation between the two genders who were affected with CLP. Huyskens et al. showed a significant delay among boys whose chronological ages ranged from 5 to 14 years. ${ }^{35}$

The control and the CLP groups were segregated into three age groups to capture the three main dental development domains (primary, mixed, and permanent dentition stages). Other studies divided their samples into individual age groups per year, ${ }^{18,30,45}$ resulting in the loss of the power needed to identify any findings. The current data were able to capture a trend showing an advanced dental age early in life and then a tendency to be delayed in the beginning of the mixed dental stage. This finding supports the observation that early dental development (early primary teeth) is not affected early in life by the CLP. It can also be related to the lack of bone and the potential scarring that prevent the eruption of permanent teeth on the affected site.

In the present study, subjects with bilateral cleft demonstrated an increased delay in dental age compared with chronological age. Although only $38.1 \%$ of the CLP group had this information clearly documented in their records, this finding was statistically significant. A study in Jordan reported a significant delay among subjects with bilateral cleft compared with those with unilateral cleft. ${ }^{40}$ Moreover, Ranta showed that the delay in dental age was prolonged with the increasing severity of the dental cleft. ${ }^{5}$ This could be due to the compounding effect of doubling the site of the cleft and its associated mechanism.

The possible reasons for the delay in dental age include genetic factors ${ }^{55}$ and nutritional status until the time of tooth formation. ${ }^{56}$ Environmental factors may also affect the normal tooth development of children with CLP. Recurrent upper respiratory infections, middle ear infections, and surgical procedures for cleft repair, in addition to the psychological effect, are all immediate postnatal factors that may have an impact on delayed dental development. ${ }^{39}$

Some of the secondary variables, such as chronological age (age groups) and laterality of the cleft site, reveal a statistically significant difference. Despite these findings, further studies are recommended where groups are recruited and assigned according to these variables. Furthermore, this research was conducted in one region of the country; an extended nationwide study highlighting that the subjects' ethnicity is preferred.

\section{CONCLUSION}

Using Demirjian's method, this study showed the control subjects' dental age as ahead of their chronological age by 8.1 months. The CLP group demonstrated delayed dental development by 9.6 months. Males with CLP had delayed dental development by 6.5 months compared with their female counterparts. Among the subjects with CLP, their dental age started to exhibit a delay at the onset of the mixed dentition stage, with a more pronounced delay as the subjects grew up.

\section{ACKNOWLedgments}

The authors would like to address Dr Emad Al-Farra's valued support and sincere coordination during the data collection phase.

\section{References}

1. Murray JC. Gene/environment causes of cleft lip and/or palate. Clin Genet 2002 Apr;61(4):248-256.

2. Tanaka K, Fujino H, et al. Cleft lip and palate: some evidences for the multifactorial trait and estimation of heritability based upon Japanese data. Jinrui Idengaku Zasshi 1969 Jun;14(1):1-9.

3. Kumar P, Hussain MT, et al. Facial clefts in Saudi Arabia: an epidemiologic analysis in 179 patients. Plast Reconstr Surg 1991 Dec;88(6):955-958. 
4. Jiroutova O, Mullerova Z. The occurrence of hypodontia in patients with cleft lip and/or palate. Acta Chir Plast 1994;36(2):53-56.

5. Ranta R. A review of tooth formation in children with cleft lip/palate. Am J Orthod Dentofacial Orthop 1986 Jul;90(1):11-18.

6. Eerens $\mathrm{K}$, Vlietinck R, et al. Hypodontia and tooth formation in groups of children with cleft, siblings without cleft, and nonrelated controls. Cleft Palate Craniofac J 2001 Jul;38(4):374-378. DOI: 10.1597/15451569_2001_038_0374_hatfig_2.0.co_2.

7. Al-Kharboush GH, Al-Balkhi KM, et al. The prevalence of specific dental anomalies in a group of Saudi cleft lip and palate patients. Saudi Dent J 2015 Apr;27(2):75-80. DOI: 10.1016/j.sdentj.2014.11.007.

8. Krailassiri S, Anuwongnukroh N, et al. Relationships between dental calcification stages and skeletal maturity indicators in Thai individuals. Angle Orthod 2002 Apr;72(2):155-166. DOI: 10.1043/0003-3219(2002)072<0155:RBDCSA $>2.0 . C O ; 2$.

9. Uysal T, Sari Z, et al. Relationships between dental and skeletal maturity in Turkish subjects. Angle Orthod 2004 Oct;74(5):657-664. DOI: 10.1043/0003-3219(2004)074<0657:RBDASM>2.0.CO;2.

10. Eid RM, Simi R, et al. Assessment of dental maturity of Brazilian children aged 6 to 14 years using Demirjian's method. Int J Paediatr Dent 2002 Nov;12(6):423-428.

11. Hegde RJ, Sood PB. Dental maturity as an indicator of chronological age: radiographic evaluation of dental age in 6 to 13 years children of Belgaum using Demirjian methods. J Indian Soc Pedod Prev Dent 2002 Dec;20(4):132-138.

12. Demirjian $\mathrm{A}$, Buschang $\mathrm{PH}$, et al. Interrelationships among measures of somatic, skeletal, dental, and sexual maturity. Am J Orthod 1985 Nov;88(5):433-438.

13. Lewis $A B, G$ arn $S M$. The relationship between tooth formation and other maturational factors. Angle Orthodontist 1960;30(2):70-77.

14. Cameriere R, Ferrante $L$, et al. Age estimation in children by measurement of open apices in teeth. Int J Leg Med 2006 Jan;120(1):49-52. DOI: 10.1007/s00414-005-0047-9.

15. Demirjian A, Goldstein $\mathrm{H}$, et al. A new system of dental age assessment. Hum Biol 1973 May;45(2):211-227.

16. Nolla C. The development of the permanent teeth. ASDCJ 1960;27: 254-266.

17. Haavikko K. Tooth formation age estimated on a few selected teeth. A simple method for clinical use. Proc Finn Dent Soc 1974 Feb;70(1):15-19.

18. Kirzioglu Z, Ceyhan D. Accuracy of different dental age estimation methods on Turkish children. Forensic Sci Int 2012 Mar 10;216(1-3): 61-67. DOI: 10.1016/j.forsciint.2011.08.018.

19. Baghdadi ZD, Pani SC. Accuracy of population-specific Demirjian curves in the estimation of dental age of Saudi children. Int J Paediatr Dent 2012 Mar;22(2):125-131. DOI: 10.1111/j.1365263X.2011.01179.x.

20. Mani SA, Naing L, et al. Comparison of two methods of dental age estimation in 7 to 15 year-old Malays. Int J Paediatr Dent 2008 Sep;18(5):380-388. DOI: 10.1111/j.1365-263X.2007.00890.x.

21. Leurs IH, Wattel $E$, et al. Dental age in Dutch children. Eur J Orthod 2005 Jun;27(3):309-314.

22. Willems G, Van Olmen A, et al. Dental age estimation in Belgian children: Demirjian's technique revisited. J Forensic Sci 2001 Jul;46(4):893-895.

23. Koshy S, Tandon S. Dental age assessment: the applicability of Demirjian's method in south Indian children. Forensic Sci Int 1998 Jun 8;94(1-2):73-85.

24. Nystrom M, Haataja J, et al. Dental maturity in Finnish children, estimated from the development of seven permanent mandibular teeth. Acta Odontol Scand 1986 Aug;44(4):193-198.

25. Mornstad $\mathrm{H}$, Reventlid $\mathrm{M}$, et al. The validity of four methods for age determination by teeth in Swedish children: a multicentre study. Swed Dent J 1995;19(4):121-130.

26. Rozylo-Kalinowska I, Kiworkowa-Raczkowska E, et al. Dental age in Central Poland. Forensic Sci Int 2008 Jan 30;174(2-3):207-216.

27. Nykanen R, Espeland L, et al. Validity of the Demirjian method for dental age estimation when applied to Norwegian children. Acta Odontol Scand 1998 Aug;56(4):238-244.
28. Liversidge HM, Speechly T, et al. Dental maturation in British children: are Demirjian's standards applicable? Int J Paediatr Dent 1999 Dec;9(4):263-269.

29. Frucht S, Schnegelsberg C, et al. Dental age in southwest Germany. A radiographic study. J Orofac Orthop 2000;61(5):318-329.

30. Lee $\mathrm{SE}$, Lee $\mathrm{SH}$, et al. Age estimation of Korean children based on dental maturity. Forensic Sci Int 2008 Jul 4;178(2-3):125-131. DOI: 10.1016/j.forsciint.2007.12.010.

31. Cheraskin E, Ringsdorf Jr WM. Biology of the orthodontic patient. 3. Relationship of chronologic and dental age in terms of vitamin C state. Angle Orthod 1972 Jan;42(1):56-59. DOI: 10.1043/0003-3219(1972)042<0056:BOTOPI>2.0.CO;2.

32. Brouwers HJ, Kuijpers-Jagtman AM. Development of permanent tooth length in patients with unilateral cleft lip and palate. Am J Orthod Dentofacial Orthop 1991 Jun;99(6):543-549.

33. Lai MC, King NM, et al. Dental development of Chinese children with cleft lip and palate. Cleft Palate Craniofac J 2008 May;45(3): 289-296. DOI: 10.1597/07-019.

34. Pham AN, Seow WK, et al. Developmental dental changes in isolated cleft lip and palate. Pediatr Dent 1997 Mar-Apr;19(2):109-113.

35. Huyskens RW, Katsaros C, et al. Dental age in children with a complete unilateral cleft lip and palate. Cleft Palate Craniofac J 2006 Sep;43(5):612-615. DOI: 10.1597/05-096.

36. Menius JA, Largent MD, et al. Skeletal development of cleft palate children as determined by hand-wrist roentgenographs: a preliminary study. Cleft Palate J 1966 Jan;3:67-75.

37. Fishman LS. Factors related to tooth number, eruption time, and tooth position in cleft palate individuals. ASDC J Dent Child 1970 Jul-Aug;37(4):303-306.

38. Bailit HL, Doykos JD, et al. Dental development in children with cleft palates. J Dent Res 1968;47(4):664.

39. Hunter WS. The effects of clefting on crown-root length, eruption, height and weight in twins discordant for cleft of lip and/or palate. Cleft Palate J 1975 Apr;12:222-228.

40. Hazza'a AM, Rawashdeh MA, et al. Dental development in children with cleft lip and palate: a comparison between unilateral and bilateral clefts. Eur J Paediatr Dent 2009 Jun;10(2):90-94.

41. de Carvalho Carrara CF, de Oliveira Lima JE, et al. Chronology and sequence of eruption of the permanent teeth in patients with complete unilateral cleft lip and palate. Cleft Palate Craniofac J 2004 Nov;41(6):642-645. DOI: 10.1597/02-085.1.

42. Heidbuchel KL, Kuijpers-Jagtman AM, et al. Dental maturity in children with a complete bilateral cleft lip and palate. Cleft Palate Craniofac J 2002 Sep;39(5):509-512. DOI: 10.1597/1545-1569_2002_039_0509_ dmicwa_2.0.co_2.

43. Borodkin AF, Feigal RJ, et al. Permanent tooth development in children with cleft lip and palate. Pediatr Dent 2008 Sep-Oct; 30(5):408-413.

44. Al-Hadlaq A, Hashim $\mathrm{H}$, et al. Interrelationship between dental maturity, skeletal maturity and chronological age in Saudi male children. Egypt Dent J 2008;54(1):55-65.

45. Al-Emran S. Dental age assessment of 8.5 to 17 year-old Saudi children using Demirjian's method. J Contemp Dent Pract 2008;9(3): 64-71.

46. Al-Tuwirqi A, Holcombe T, et al. A study of dental development in a Caucasian population compared with a non-Caucasian population. Eur Arch Paediatr Dent 2011 Feb;12(1):26-30.

47. Qudeimat MA, Behbehani F. Dental age assessment for Kuwaiti children using Demirjian's method. Ann Hum Biol 2009 Nov-Dec; 36(6):695-704. DOI: 10.3109/03014460902988702.

48. Pagano MaKg. Principles of biostatistics; numerical summary measures. Duxbury Press, 2000;p. 42.

49. Ongkosuwito EM, de Gijt P, et al. Dental development in hemifacial microsomia. J Dent Res 2010 Dec;89(12):1368-1372. DOI: $10.1177 / 0022034510378425$.

50. De Coster PJ, Mortier G, et al. Cranial suture biology and dental development: genetic and clinical perspectives. J Oral Pathol Med 2007 Sep;36(8):447-455. DOI: 10.1111/j.1600-0714.2007.00553.x. 
51. Thorson J, Hagg U. The accuracy and precision of the third mandibular molar as an indicator of chronological age. Swed Dent J 1991;15(1): 15-22.

52. Fanning EA. Most cited: number 1. A longitudinal study of tooth formation and root resorption. N Z Dent J 2008 Jun;104(2): $60-61$.

53. Staaf $\mathrm{V}$, Mornstad $\mathrm{H}$, et al. Age estimation based on tooth development: a test of reliability and validity. Scand J Dent Res 1991 Aug;99(4):281-286.
54. Galic I, Vodanovic M, et al. Accuracy of Cameriere, Haavikko, and Willems radiographic methods on age estimation on BosnianHerzegovian children age groups 6-13. Int J Legal Med 2011 Mar;125(2):315-321. DOI: 10.1007/s00414-010-0515-8.

55. Jordan RE, Kraus BS, et al. Dental abnormalities associated with cleft lip and/or palate. Cleft Palate J 1966 Jan;3:22-55.

56. Ranta R. Asymmetric tooth formation in the permanent dentition of cleft-affected children. An orthopantomographic study. Scand J Plast Reconstr Surg 1973;7(1):59-63. 